INDONESIAN HEALTH ISSUE

\title{
Pengaruh Terapi Kompres Hangat Dan Massage Effleurage Terhadap Pengurangan Nyeri Kala I Fase Aktif Persalinan
}

\author{
Riska Susanti Pasaribu ${ }^{1}$, Ridesman ${ }^{2}$, Deby Cyntia Yun ${ }^{3}$, Mei Anita Hotmaida ${ }^{4}$ \\ 1-2 STIKes Mitra Husada Medan \\ Email korespondensi:estersimanullang13.es@gmail.com \\ No HP: 081269706911
}

\begin{tabular}{l}
\hline ARTICLE INFO \\
Received \\
01 Januari 2022 \\
Accepted \\
14 Februari 2022 \\
Published \\
19 Februari 2022 \\
\hline
\end{tabular}

Kata Kunci:

Kompres Hangat;

Massase Efflurage,

Nyeri Persalinan

\section{Keywords:}

Warm Compress, Efflurage Massage, Labor Pain

\begin{abstract}
ABSTRAK
Latar Belakang: Persalinan merupakan suatu proses yang alami yang akan berlangsung dengan sendirinya tetapi proses persalinan pada manusia setiap saat terancam penyulit yang mebahayakan ibu maupun janinnya sehingga memerlukan pengawasan, pertolongan dan pelayanan kesehatan dengan fasilitas kesehatan yang memadai. Pada persalinan dapat menimbulkan trauma pada ibu karena nyeri yang dialaminya. Berdasarkan data klinik, penyulit persalinan $87 \%$ kemungkinan bisa terjadi. Hasil tersebut berpotensi proses persalinan lebih lama dan lebih beresiko untuk terjadi kematian apabila tidak ditangani dengan tepat. Hal mengakibatkan beberapa mengalami trauma untuk hamil dan melahirkanlagi karena takut akan mengalami nyeri yang sama. Metode: Jenis penelitian penelitian quasi eksperimental kuantitatif dengan rancangan one group post test with control yaitu suatu penelitian yang dilakukan dengan subjek eksperimen pada kelas eksperimen dan kelas control tidak dipilih secara acak. Hasil: Penelitian bahwa pengaruh kompres hangat terhadap pengurangan nyeri persalinan kala I fase aktif sebelum dan sesudah diberikan kompres hangat pada kelompok kontrol dan dilakukan uji paired sample t-test didapatkan hasil untuk nyeri persalinan dengan nilai $P=0,001$, artinya $p<0,05$, menyatakan terdapat pengaruh kompres hangat dalam mengurangi nyeri pesalinan kala satu persalinan. Dan pengaruh massase efflurage terhadap pengurangan rasa nyeri persalinan kala I fase aktif sebelum dan sesudah diberikan massase efflurage pada kelompok intervensi dan dilakukan uji paired sample t-test didapatkan hasil untuk pengurangan nyeri persalinan dengan nilai $P=0,001$ artinya $p<0,05$. Kesimpulan: Disarankan bagi petugas kesehatan melakukan kompres hangat dan massase efflurage untuk mengurangi rasa nyeri saat proses persalinan kala I fase aktif.
\end{abstract}

ABSTRACT
Background: Labor is a natural process that will take place by itself, but
the process of childbirth in humans is at any time threatened with
complications that endanger the mother and fetus so that it requires
supervision, assistance and health services with adequate health
facilities. In childbirth can cause trauma to the mother because of the pain
she experiences. Based on clinical data, labor complications are $87 \%$
likely to occur. These results have the potential for a longer labor process
and a higher risk of death if not handled properly. This resulted in some
experiencing trauma to get pregnant and give birth again for fear of
experiencing the same pain. Method: This type of research is a


quantitative quasi-experimental research with a one group post test with control design, which is a study conducted with experimental subjects in the experimental class and the control class not chosen randomly. Results: The study that the effect of warm compresses on reducing labor pain in the first stage of the active phase before and after being given warm compresses in the control group and a paired sample t-test was carried out. the effect of warm compresses in reducing labor pain in the first stage of labor. And the effect of massage efflurage on the reduction of labor pain in the active phase of the first stage before and after being given massage efflurage in the intervention group and a paired sample ttest was performed. The result was a reduction in labor pain with a value of $P=0.001$ meaning $p<0.05$.Conclusion: It is recommended for health workers to do warm compresses and massage efflurage to reduce pain during the active phase of the first stage of labor. 


\section{PENDAHULUAN}

Pada persalinan dapat menimbulkan trauma pada ibu karena nyeri yang dialaminya. Beberapa ibu bahkan ada yang trauma untuk hamil dan melahirkanlagi karena takut akan mengalami nyeri yang sama. Bagi ibu yang pernah melahirkan, nyeri persalinan merupakan nyeri yang paling menyakitkan apalagi bagi ibu-ibu yang baru pertama kali merasakannya (Trirestuti, 2018). Data WHO 2018, lebih dari 140 juta wanita melahirkan setiap tahun. Beberapa kasus kelahiran bukanlah peristiwa membahayakan tetapi menjadi suatu masa yang penuh dengan rasa nyeri, rasa takut, penderitaan bahkan kematian. Hal inilah yang menyebabkan banyaknya permintaan untuk melakukan Sectio Caesaria (SC) (Trirestuti, 2018 ).

Rasa nyeri diperlukan untk mengenali adanya kontraksi uterus selama proses persalinan, tetapi kadang rasa nyeri tersebut bis menimbulkan akibat patologis yang dirasakan terus menerus, ditambah rasa cemas dan ketakutan yang dialamai ibu bersalin. Hal ini dapat mengakibatkan keletihan sehingga mengakibatkan penurunan kontraksi uterus dan proses persalinan pun berlangsung lebih lama. Persalinan yang lama (Prolonged Labour) dapat membahayakan ibu dan janin (Rahman, 2017).

Sensasi nyeri yang dirasakan ibu hamil akan berbeda kadarnya, ada yang benar-benar merasakan sakit yang luar biasa, namun juga banyak merasa nyeri yang tidak terlalu lama. Tentunya hal ini banyak factor penyebabnya, dimulai dari tindakan dokter / bidan dalam menolong persalinan, partus lama, ibu melahirkan tanpa pendamping, keletihan, tidak siap melahirkan, stress, cemas dan tegang selama kontraksi (Trirestuti, 2018).

Upaya untuk menurunkan nyeri pada persalinan dapat dilakukan baik secara farmakologi maupun non farmakologi. Cara menghilangkan sakit persalinan secara farmakologi adalah dengan pemberian analgetik atau obat penghilang rasa sakit, suntikan epidural, blok saraf perineal dan pudendal, menggunakan mesin Transcutaneus Electrical Nerve Stimulation (TENS) untuk merangsang tubuh memproduksi senyawa penghilang rasa sakit. Secara non farmakologis penatalaksanaannya antara lain dengan menghadirkan pendamping persalinan, perubahan posisi dan pergerakan, sentuhan, massage, hipnotis, kompres hangat dan dingin, berendam air hangat, terapi akupuntur, visualisasi dan pemusatan perhatian dan music (Trirestuti, 2018).

Berdasarkan data yang didapat dari hasil survei di Klinik Bersalin Heny Kasih Kota Medan, bahwa ada sebanyak 18 dari 23 orang ibu mengatakan merasakan kesulitan saat proses bersalin. Dari uraian diatas penulis tertarik untuk melakukan penelitian tentang "Pengaruh kompres hangat dan massage effleurage terhadap pengurangan rasa nyeri persalinan kala 1 fase aktif di Klinik Bersalin Heny Kasi Kota Medan Tahun 2021."

\section{METODE PENELITIAN}

Penelitian ini menggunakan metode quasi eksperimental kuantitatif dengan rancangan one group post test with control dimana subjek eksperimen pada kelas eksperimen dan kelas control tidak dipilih secara acak. Sample yang diteliti adalah semua lbu bersalin yang melahirkan di Klinik Bersalin Heny Kasih berjumlah 30 orang. Analisis penelitian digunakan untuk memperoleh gambaran distribusi 
frekuensi atau besarnya proporsi berdasarkan variabel yang diteliti. Analisis dilakukan dengan menggunakan uji paired pada tingkat kepercayaan $95 \%(\alpha=0,05)$, sehingga apabila ditemukan hasil analisis statistik $p<0,05$ maka variabel tersebut dinyatakan berhubungan secara signifikan.

\section{HASIL PENELITIAN}

\section{a. Analisis Bivariat}

Hasil penelitian bahwa kompres hangat berpengeruh dalam mengurangi nyeri persalinan kala I sebelum dan sesudah diberikan kompres hangat pada kelompok kontrol dengan dilakukan uji paired sample t-test didapatkan hasil nyeri persalinan dengan nilai $P=0,001$, artinya $p<0,05$. Berdasarkan hasil uji paired test dapat dilihat pada tabel 1. Berikut ini

Tabel 1. Pengaruh Kompres Hangat terhadap pengurangan rasa nyeri persalinan kala I fase aktif di Klinik Bersalin Heny Kasih Tahun 2021

\begin{tabular}{lccc}
\hline Nyeri Persalinan & Mean & SD & Nilai P \\
\hline Pre-test & 25,300 & 6.534 & 0,001 \\
Post-test & & & \\
\hline
\end{tabular}

Hasil penelitian menunjukkan bahwa massase efflurage memiliki pengaruh terhadap pengurangan rasa nyeri persalinan kala I fase aktif pada ibu sebelum dan sesudah diberikan massase efflurage pada kelompok intervensi dan dilakukan uji paired sample t-test didapatkan hasil untuk pengurangan nyeri persalinan dengan nilai $\mathrm{P}=$ 0,001 artinya $p<0,05$.

2. Berdasarkan hasil uji paired test dengan nilai signifikansi yaitu $0,00<0,05$, maka Ho ditolak dan Ha diterima. Kesimpulannya ada pengaruh massase Efflurage terhadap pengurangan rasa nyeri persalinan kala I fase aktif. Hasil analisis dapat dilihat pada tabel 2. berikut ini :

Tabel 2. Pengaruh Massase Efflurage terhadap pengurangan rasa nyeri persalinan kala I fase aktif di Klinik Bersalin Heny Kasih Tahun 2021

\begin{tabular}{lccc}
\hline Keluhan Fisik & Mean & SD & Nilai P \\
\hline Pre-test & 25,633 & 15,806 & 0,001 \\
Post-test & & & \\
\hline
\end{tabular}

3. Dari hasil penelitian didapatkan pada perbedaan pengaruh kompres hangat dan massase efflurage dalam mengurangi rasa nyeri persalinan kala I fase aktif dan dilakukan uji independent sample $\mathrm{t}$ test didapatkan hasil bahwa tidak terdapat perbedaan pengaruh antara kompres hangat dan massase efflurage dalam mengurangi nyeri persalinan persiapan kala I fase aktif. Hasil analisis dapat dilihat pada tabel 3. berikut ini : 
Tabel 3. Perbedaan Pengaruh Kompres hangat dan Massase Efflurage Hamil Terhadap Pengurangan rasa nyeri persalinan kala I fase aktif di Puskesmas Panei Tongah Kecamatan Panei Kabupaten Simalungun Tahun 2021

\begin{tabular}{lllll}
\hline $\begin{array}{l}\text { Pengurangan Rasa } \\
\text { Nyeri }\end{array}$ & $\mathrm{N}$ & Mean & $\mathrm{T}$ & Nilai P \\
\hline Kelompok kontrol & 15 & 14,70 & 1,593 & 0,122 \\
Kelompok intervensi & 15 & & & \\
\hline
\end{tabular}

\section{PEMBAHASAN}

Penurunan intensitas nyeri pada ibu bersalin kala I fase aktif yaitu dari 30 responden ibu bersalin sebagian besar 14 responden (46,7\%) mengalami nyeri sedikit sesudah pemberian kompres hangat dan massage Effleurage. Hasil penelitian ini didukung dengan penelitian yang dilakukan oleh Siregar (2016), penurunan skala nyeri sebelum dan sesudah dilakukan terapi kompres hangat di Klinik Nirmala Medan menunjukkan ada pengaruh yang signifikan sebelum dan sesudah pemberian kompres hangat pada ibu bersalin kala I fase aktif dengan hasil p-value 0,000 .

Penggunaan kompres hangat untuk area yang tegang dan nyeri dianggap mampu meredakan nyeri. Hangat mengurangi spasme otot yang disebabkan oleh iskemia yang merangsang neuron yang memblok transmisi lanjut rangsang nyeri menyebabkan vasodilatasi dan peningkatan aliran darah ke area yang dilakukan pengompresan (Walsh, 2017). Hasil penelitian ini juga diperkuat dengan penelitian sebelumnya yang dilakukan oleh Manurung (2015) Tehnik kompres hangat dan massage effleurage selama proses persalinan dapat mempertahankan komponen sistem vaskuler dalam keadaan vasodilatasi sehingga sirkulasi darah ke otot panggul menjadi homeostatis serta dapat mengurangi kecemasan dan ketakutan serta beradapatasi dengan nyeri selama proses persalinan.

Menurut asumsi penulis penelitian ini dilakukan dengan melakukan intervensi terhadap ibu bersalin kala I fase aktif dengan melakukan pemberian kompres hangat di bagian punggung bawah dan massage effleurage. Berdasarkan hasil penelitian yang diperoleh yaitu terlihat adanya penurunan intensitas nyeri pada ibu bersalin kala I fase aktif. Berdasarkan wawancara kepada responden sebelum dilakukan intervensi pemberian kompres hangat dan massage effleurage berdasarkan intensitas nyeri yang dialami oleh responden yaitu sebagian besar 15 responden mengalami nyeri sekali dan setelah dilakukan intervensi pemberian terapi 14 responden mengalami penurunan rasa nyeri.

Pemberian kompres hangat dan massage effleurage terhadap pengurangan rasa nyeri persalinan kala I fase aktif di Wilayah Kerja Puskesmas Panei Tongah Kecamatan Panei Kabupaten Simalungun tahun 2021, setelah dianalisis menggunakan uji paired didapatkan hasil diperoleh dengan nilai $p$ value 0,001 dengan taraf signifikan $5 \%$ dan dapat disimpulkan sig. $\mathrm{p}$ value $\leq 0,05$ maka $\mathrm{Ho}$ ditolak dan Ha diterima dengan demikian ada pengaruh. 
Hasil penelitian ini juga sejalan dengan penelitian sebelumnya yang dilakukan oleh Siregar (2016) tentang pemberian kompres hangat pada ibu bersalin kala I berpengaruh terhadap pengurangan nyeri persalinan di Klinik Nirmala Medan dengan nilai rata-rata sebelum intervensi mencapai $8,40 \%$ dan sesudah intervensi nilai rata-rata menjadi $4,75 \%$. Bahwa kompres hangat bermanfaat untuk meningkatkan suhu kulit lokal, melancarkan sirkulasi darah dan menstimulasi pembuluh darah, mengurangi spasme otot dan meningkatkan ambang nyeri, menghilangkan sensasi rasa nyeri, merangsang peristaltik usus, pengeluaran getah radang serta memberikan ketenangan dan kenyamanan pada ibu inpartu. Hasil penelitian tersebut menunjukkan ada pengaruh yang signifikan pemberian kompres hangat terhadap pengurangan nyeri persalinan kala I dengan nilai $p$ value $=0,000, p$ value $<0,05$.

Temuan di atas sejalan dengan hasil penelitian Stang Abdul Rahman (2017) yang berjudul Penurunan Nyeri Persalinan dengan kompres hangat dan Massage Effleurage dimana didapatkan hasil, terdapat penurunan skala nyeri persalinan sebelum dan setelah terapi pada kelompok intervensi. Sebelum terapi, skala nyeri terendah adalah 6 dan skala nyeri tertinggi adalah 8 dengan ratarata skala nyeri adalah 7,00. Sedangkan setelah terapi, skala nyeri terendah adalah 3 dan skala nyeri tertinggi adalah 6 dengan rata-rata skala nyeri adalah 4,14. Ada pengaruh kompres hangat dan massage effleurage terhadap penurunan nyeri persalinan pada primipara selama kala satu persalinan setelah dilakukan intervensi dengan nilai $p=0,000$. Kompres hangat dan massage effleurage dapat menurunan nyeri persalinan sebesar 2,86. Saran bagi pihak Puskesmas Plus Bara-Baraya Makassar khususnya tenaga kesehatan yang bertugas di ruang persalinan agar dapat menerapkan penatalaksanaan terapi kompres hangat dan massage effleurage kepada ibu primipara selama kala satu persalinan sebanyak masing-masing dua kali pemberian atau sesuai dengan keluhan ibu agar rasa nyeri yang dirasakan ibu dapat berkurang.

Hasil penelitian ini juga sejalan dengan hasil penelitian yang dilakukan oleh Mutia, dkk., tahun 2015 mendapatkan hasil bahwa terdapat perbedaan rerata derajat nyeri setelah kompres panas dan dingin dengan nilai $p=0,003$. Terdapat perbedaan selisih derajat nyeri kompres panas dan dingin $p=0,001$. Terdapat pengaruh pemberian kompres panas dan dingin terhadap penurunan nyeri persalinan.

\section{SIMPULAN DAN SARAN}

\section{SIMPULAN}

Dari hasil penelitian pengaruh pemberian kompres hangat dan massage effleurage terhadap pengurangan rasa nyeri persalin kala I fase aktif di Klinik Bersalin Heny Kasih Tahun 2021, maka dapat disimpulkan sebagai berikut : Ada pengaruh yang signifikan kompres hangat terhadap pengurangan nyeri persalinan kala I fase aktif di Puskesmas Panei Tongah Tahun 2021, ada pengaruh yang signifikan massase efflurage terhadap pengurangan nyeri persalinan kala I fase aktif 
di Klinik Bersalin Heny Kasih Tahun 2021. Berdasarkan uji paired yang dilakukan maka hasil penelitian yang ditemukan adalah tidak ada perbedaan pengaruh yang signifikan kompres hangat terhadap pengurangan nyeri persalinan kala I fase aktif di Klinik Bersalin Heny Kasih Tahun 2021. Bagi Masyarakat untuk dapat memahami penatalaksanaan kompres hangat dan massase efflurage untuk mengurangi rasa nyeri persalinan.

\section{SARAN}

Disarankan untuk Pimpinan Klinik Bersalin Heny Kasih agar melaksanakan kompres hangat dan melakukan massase efflurage kepada ibu bersalin untuk memberikan rasa nyaman dan mengurangi rasa nyeri persalinan kala I fase aktif. Disarankan untuk Pimpinan Institusi agar lebih meningkatkan mutu pendidikan dalam proses pembelajaran teori maupun praktik. Agar mahasiswa dapat meningkatkan pengetahuan dan wawasan tentang penatalaksanaan kompres hangat dan massase efflurage. Disarankan kepada peneliti selanjutnya untuk melakukan penelitian sejenis dengan skala penelitian yang lebih luas untuk mendapatkan hasil penelitian yang lebih akurat.

\section{DAFTAR PUSTAKA}

Bobak. 2015. Keperawatan Maternitas. Alih Bahasa: Wijayarini. A. M. Jakarta: EGC. Danuatmaja Bonny, Meiliasari Mila. 2015. Persalinan Normal Tanpa Rasa Sakit.Jakarta : Puspa Swara.

Maryunani, A. 2016. Nyeri Dalam Pesalinan (Teknik dan Cara Penanganannya ). Jakarta : Trans Info Media.

Oktasari G, Misrawati, Utami GT. 2015. Perbandingan efektivitas kompres hangat dan kompres dingin terhadap penurunan dismenorea pada remaja putri.JOM.;1(1):1-8

Perry dan Potter. 2016. Fundamental Keperawatan, Edisi 4, EGC, Jakarta.

Potter, P.A dan Perry, A.G. 2015. Buku ajar Fundamental Keperawatan : Konsep, Proses, dan Praktik Volume 1. Ed. 4 .Jakarta : Penebit Buku Kedokteran EGC.

Yani DP, Khasanah U.2016. Pengaruh pemberian kompres air hangat terhadap rasa nyaman dalam proses persalinan kala I fase aktif. J UNIPDU.(http://www.journal.unipdu.ac.id)

Yesie Aprillia. 2015. Hipnostetri :Rileks, Nyaman dan Aman Saat Hamil dan Melahirkan. Jakarta: Gagas Medi.

Yuliatun, Laily.2018. Penanganan Nyeri Persalinan Dengan Metode Nonfarmakologi

Varney H, Kriebs MJ, Gegor CL.2016. Buku ajar asuhan kebidanan. 4th ed. Jakarta: EGC.

Wahyuni, Intan Dewi. 2014. Pengaruh Pemberian Kompres Hangat Terhadap

Penurunan Skala Nyeri Pada Ibu Bersalin Di RB. Ananda Desa Jabon Kecamatan

Mojoanyar Kabupaten Mojokerto. http://repository.poltekkesmajapah

it.ac.id/index.php/PUBKEB/article 